This item was submitted to Loughborough's Research Repository by the author.

Items in Figshare are protected by copyright, with all rights reserved, unless otherwise indicated.

\title{
Relationships between temperament and eating behaviours in young children
}

PLEASE CITE THE PUBLISHED VERSION

http://dx.doi.org/10.1016/j.appet.2011.02.005

PUBLISHER

(C) Elsevier Ltd.

VERSION

AM (Accepted Manuscript)

LICENCE

CC BY-NC-ND 4.0

REPOSITORY RECORD

Haycraft, Emma, Claire V. Farrow, Caroline Meyer, Faye Powell, and Jacqueline Blissett. 2019. "Relationships Between Temperament and Eating Behaviours in Young Children". figshare.

https://hdl.handle.net/2134/11190. 
This item was submitted to Loughborough's Institutional Repository (https://dspace.lboro.ac.uk/) by the author and is made available under the following Creative Commons Licence conditions.

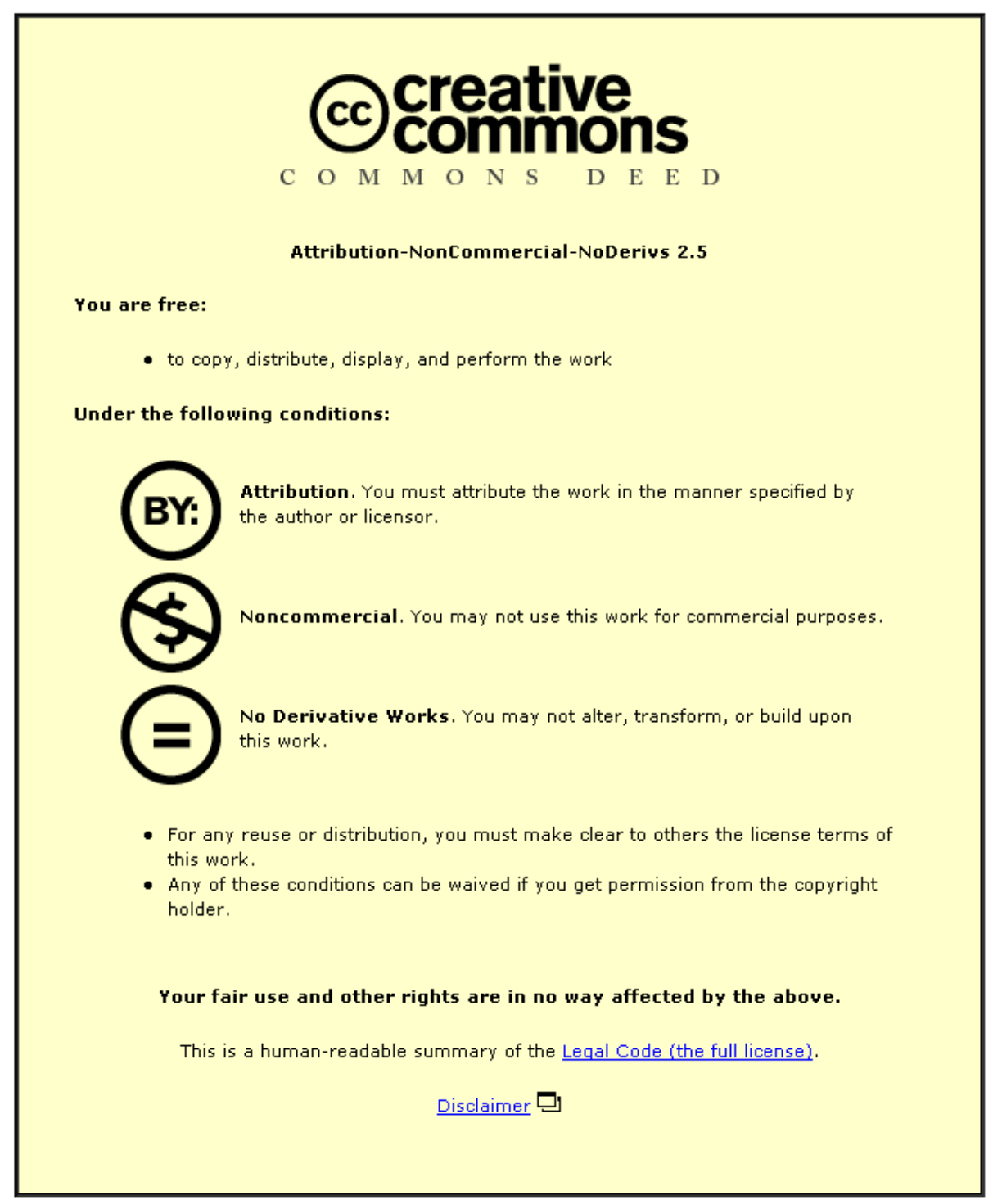

For the full text of this licence, please go to: http://creativecommons.org/licenses/by-nc-nd/2.5/ 
Running head: CHILDREN'S EATING AND TEMPERAMENT

Relationships between temperament and eating behaviours in young children

\author{
Emma Haycraft, $\mathrm{PhD}^{\mathrm{a}} *$ \\ Claire Farrow, $\mathrm{PhD}^{\mathrm{a}}$ \\ Caroline Meyer, $\mathrm{PhD}^{\mathrm{a}}$ \\ Faye Powell, BSc ${ }^{\mathrm{a}}$ \\ Jackie Blissett, $\mathrm{PhD}^{\mathrm{b}}$
}

${ }^{a}$ Loughborough University Centre for Research into Eating Disorders, School of Sport,
Exercise and Health Sciences, Loughborough University, Leicestershire LE11 3TU, UK..
${ }^{\mathrm{b}}$ School of Psychology, University of Birmingham, Edgbaston, Birmingham B15 2TT, UK

*Address correspondence to: Dr Emma Haycraft: E.Haycraft@lboro.ac.uk;

NOT FOR PUBLICATION: Tel. +44(0)1509 228160; Fax. +44(0)1509 3340.

Acknowledgements: We thank Laura Williams and Sophie Howes for their assistance with the data collection. 


\begin{abstract}
This study examined the associations between eating behaviours and temperament in a sample of young children. Mothers $(\mathrm{N}=241)$ of children aged 3-8 years completed measures of their children's eating behaviours and temperament and reported their child's height and weight. Children with more emotional temperaments were reported to display more food avoidant eating behaviours. Shyness, sociability and activity were not related to children's eating behaviours. Higher child BMI was related to more food approach eating behaviours but BMI was unrelated to child temperament. Future research should explore more specifically how emotional temperaments might influence child eating behaviour.
\end{abstract}

Keywords: emotionality, activity, sociability, shyness, temperament, eating behaviour, children, feeding problems, fussy eating, overweight. 
Relationships between temperament and eating behaviours in young children

Examining the factors that influence children's eating behaviours is an important priority given the prevalence of childhood obesity (e.g., Lobstein, Baur \& Uauy, 2004). One factor which might be associated with young children's eating behaviours is their temperament. Temperament has been defined as "personal characteristics that are biologically based, are evident from birth onwards, are consistent across situations and have some degree of stability" (Schaffer, 2006, p.70). Differences in individuals' temperament may determine why some children, but not others, are at risk of overweight or feeding problems, why certain children have better emotional relationships with food than others, and why parents use particular feeding practices with their children.

Previous research has established links between temperament and eating behaviours in infants. For example, difficult infant temperament has been associated with negative mealtimes and food refusal in young children (Farrow \& Blissett, 2006), and with the feeding practices that parents employ (e.g., Blissett \& Farrow, 2007). In addition, feeding difficulties have been found to be more prevalent in children who are unsociable, difficult or demanding (e.g., Hagekull, Bohlin \& Rydell, 1997; Pliner \& Loewen, 1997) and parental reports of having a shy, emotional child have been related to children's unwillingness to try new foods (Pliner \& Loewen, 1997).

Temperament traits have also been related to obesity and overweight in children and to disordered eating attitudes and behaviours in infants, adolescents and adults. For instance, children's emotional temperament has been implicated in the development of overweight, having been shown to mediate the relationship between child and parent overweight (Agras, Hammer, McNicholas \& Kraemer, 2004). Furthermore, temperamental differences have been identified between toddlers with 'infantile anorexia' and a healthy eating control group 
(Chatoor, Ganiban, Hirsch, Borman-Spurrell \& Mrazek, 2000), with toddlers with infantile anorexia being described by their caregivers as more difficult and more negative. In addition, childhood temperament (specifically higher levels of negative emotionality) has been related to the development of later eating concerns (Martin et al., 2000). Finally, in adults, temperamental traits such as impulsivity have been linked with disordered eating attitudes and behaviours (e.g., Wonderlich, Connolly, \& Stice, 2004). Thus, there is evidence to suggest that an individual's temperament may be associated with later eating-related problems.

While some work has examined temperament and eating in infants, or with older adolescent or adult samples, there is a paucity of literature which has examined these associations in school-age children, when children's autonomy over eating becomes more evident. The current study therefore aimed to address this gap in the literature by first examining associations between young children's temperament, as reported by their parents using a well-established measure, and a range of typical eating behaviours, assessed via the Child Eating Behaviour Questionnaire (CEBQ; Wardle, Guthrie, Sanderson \& Rapoport, 2001). A second aim was to examine associations between children's BMI with parents' reports of their children's eating behaviours and temperament. In line with other research that has used the CEBQ (e.g. Webber, Hill, Saxton, Van Jaarsveld \& Wardle, 2009), children's eating behaviours were considered in terms of children's food approach eating behaviours (i.e. those eating behaviours previously found to link to greater food intake and higher weight in children, e.g., enjoyment of food) and food avoidance behaviours (those behaviours that are related to lower food intake and lower weight status, e.g., food fussiness). In relation to the study's first aim, it was hypothesised that children who were reported as having a more difficult temperament (e.g., more emotional, less sociable) would have more food avoidant and less food approach eating behaviours (e.g., higher levels of fussiness, 
lower levels of enjoyment). For the second aim, it was hypothesised that children with a higher BMI would have higher reported levels of food approach eating behaviours (e.g., more food responsiveness) and also more emotional temperaments.

\section{METHOD}

\section{Participants}

Two hundred and eighty-two parents of children aged 3-8 years completed and returned questionnaires. Participants were excluded if information was missing about the age of the child $(n=14)$ or either parent or child gender $(n=10)$. Questionnaires completed by a father/male caregiver $(n=17)$ were also excluded given previous findings that suggest mothers eat more frequently with their children than fathers do (e.g., Haycraft \& Blissett, 2008). This left a final sample of 241 mothers. The mean age of these mothers was 36 years (SD 5.72) and they had a mean Body Mass Index (BMI) of 24 (SD 4.17), indicating generally healthy weight. Mothers reported an average of 4 years of education after the age of 16 (SD 2.82). Of the children reported on in this study, $55 \%$ were male $(n=133)$ and $45 \%$ were female $(\mathrm{n}=108)$. The mean age was 5 years for both the boys (SD 1.39) and the girls (SD 1.46). Where children's height and weight data were available (n=142) BMI Z-scores, accounting for child age and gender, were calculated using the Child Growth Foundation Reference Curves Disc (Child Growth Foundation, 1996). The mean BMI Z-score was -.05 (SD 2.09) for the boys and -.14 (SD 1.44) for the girls, indicating healthy weights. Of the sample of children for whom BMI data were available, $25 \%$ were underweight $(n=35), 51 \%$ were healthy weight $(n=73)$, and $24 \%$ were overweight/obese $(n=34)$. Ethnicity data were not collected, but the nurseries/schools involved in this study served mostly white, middle class neighbourhoods. 


\section{Measures and procedure}

Following Institutional Review Board ethical approval, questionnaire packs were distributed via nurseries/schools to parents with children in the target age range. After giving informed consent, participants provided background information about themselves and their child (their age, height, weight, number of years of education after age 16, and their child's age, height and weight) and completed the questionnaires listed below. Responses were returned either in an envelope to their child's nursery/school or directly to the researcher using a postage-paid envelope.

\section{Children's Eating Behaviour Questionnaire (CEBQ; Wardle et al., 2001)}

The CEBQ is a 35 item questionnaire which examines children's food approach and food avoidant eating behaviours. The food approach subscales are: Food responsiveness (e.g., If allowed to, my child would eat too much); Emotional over-eating (e.g., My child eats more when worried); Enjoyment of food (e.g., My child looks forward to mealtimes); Desire to drink (e.g., My child is always asking for a drink). The four food avoidant subscales are: Satiety responsiveness (e.g., My child gets full up easily); Slowness in eating (e.g., My child takes more than 30 minutes to finish a meal); Emotional under-eating (e.g., My child eats less when upset); and, Food fussiness (e.g., My child is difficult to please with meals). Questions are responded to on a 5-point Likert scale (never to always) and five items are reverse scored. Mean scores are calculated from the responses to each subscale and possible scores range from one to five. Higher scores indicate a greater prevalence of that particular eating behaviour. The CEBQ has been found to display good internal validity and reliability when completed by parents of young children (Wardle et al., 2001). In the current sample, Cronbach's alpha values are all good, ranging from .70 to .89 . 


\section{EAS Temperament Survey for children (EAS; Buss \& Plomin, 1984)}

The EAS comprises 20 statements assessing four dimensions of children's temperament: Shyness (e.g., Child takes a long time to warm up to strangers); Emotionality (e.g., Child gets upset easily); Sociability (e.g., Child likes to be with people); and Activity (e.g., Child is always on the go). Parents respond on a 5-point Likert scale to indicate how characteristic behaviours are of their child. A mean score is calculated for each subscale with possible subscale scores from one to five. Higher scores indicate that the trait is more typical of the child. The measure has been found to have adequate psychometric properties with this age group (e.g., Mathiesen \& Tambs, 1999). Cronbach's alpha values ranged from .58 (sociability) to .83 (emotionality) with the current sample.

\section{Data analysis}

Given the relatively broad age range of the children reported on in this study, preliminary Pearson's correlations were run to test for significant associations between child age with the study's key variables (children's eating behaviours and temperament). Child age was significantly related to several CEBQ and EAS subscales. Data are not shown here, but significant negative correlations were found between child age and satiety responsiveness, slowness in eating, emotional under-eating, food fussiness, desire to drink and emotionality. In addition, t-tests examined differences in child age and in mothers' reports on the CEBQ and EAS for girls and for boys. The t-tests revealed that girls were rated as significantly more emotional than boys $(t(237)=-2.53, \mathrm{p}<.01$; girls' mean $=2.74$, boys' mean $=2.43)$ and boys as significantly more active than girls $(t(237)=2.32, \mathrm{p}<.01$; girls' mean $=4.05$, boys' mean $=4.26$ ). There were no other significant differences between girls' and boys' age, temperaments or eating behaviours in this sample. In view of the findings from these preliminary analyses, partial correlations controlling for child age and gender were run on the 
sample as a whole. Significance values were set at $p<.01$, to account for the multiple tests being carried out.

\section{RESULTS}

Descriptive statistics for the children in this study can be seen in Table 1.

\section{---TABLE 1 ABOUT HERE---}

Scores on the CEBQ and EAS for children in this sample are in line with previous studies using these measures in similar samples (e.g., Mathiesen \& Tambs, 1999; Wardle et al., 2001).

Associations between children's temperament and eating behaviours, after controlling for child age and gender, can be seen in Table 2 .

\section{---TABLE 2 ABOUT HERE---}

Shyness, sociability and activity were not significantly related to any eating behaviours. However, greater emotionality was linked to lower enjoyment of food and to greater reported emotional over- and under-eating, satiety responsiveness, slowness in eating and fussiness. Child BMI was positively related to food responsiveness, emotional overeating and desire to drink and was negatively related to slowness in eating. Child BMI was not significantly related to any temperament traits.

\section{DISCUSSION}

This study aimed to examine the associations between temperament and eating behaviours in a sample of pre-school and school-age children. Some support was found for the hypothesis that children with more difficult temperaments would have more food avoidant eating behaviours, with several significant relationships being identified between a 
more emotional child temperament and food avoidant eating behaviours in this sample. The prediction that children with a higher BMI would have greater reported levels of food approach eating behaviours was generally supported but the predicted association between BMI and a more emotional temperament did not receive support.

Interestingly, child emotionality was the only temperament trait to significantly correlate with children's eating behaviours. More emotional temperaments were related to less enjoyment of food and to greater fussy eating, slower eating and higher satiety responsiveness as well as to more emotional over- and under-eating. These findings support and extend previous work implicating emotionality not just in feeding difficulties such as fussy and slow eating (Pliner \& Loewen, 1997) but also in more generic eating behaviour constructs such as enjoyment of food and responding to fullness. Furthermore, it is interesting that emotional overeating was the only food approach behaviour to be associated with emotionality. Given that previous literature has suggested that emotional over-eating is also associated with parental use of food to regulate emotion (Blissett, Haycraft \& Farrow, 2010), this may suggest an interactive model for the development of emotional eating where child emotional temperament may elicit parental use of food to regulate the child's emotional states.

For the children in this sample, sociability, shyness and activity were unrelated to their eating behaviours. Such findings support previous work which found that social factors were not predictive of disordered eating in adolescent girls or boys (Martin et al., 2000). However, children's BMI was significantly related to more obesogenic eating behaviours, as evidenced by the significant associations with three of the four food approach subscales. In particular, food responsiveness, emotional over-eating and desire to drink, all of which have previously been associated with higher weight status (e.g., Webber et al., 2009), were related to increased child BMI in this sample. Child BMI was also related to lower levels of slowness 
in eating, again supporting previous work which has found faster eating to be linked to overweight (e.g., Barkeling, Ekman \& Rossner, 1992).

Contrary to our predictions, children's BMI was not related to their temperament for children in this sample. It is possible that the relationship between temperament and weight may be indirect, as was found by Agras et al. (2004). It should also be noted that the children in this sample were generally reported to have healthy weights and that links between temperament and eating behaviours might be more pronounced in children who are over- or underweight. Furthermore, children's BMI was obtained by parental self-report which, although previously shown to be reliable (e.g., Haycraft \& Blissett, 2008), resulted in considerable missing child BMI data within this sample. Work with objective BMI measurements is therefore required to further explore the potential associations between children's temperaments and BMI.

This study highlights important associations between children's temperament and their eating behaviours. Limitations of this work include the reliance on parents' self-reports, the examination of only four temperament traits, and the absence of objective height and weight measurements. Furthermore, the generalisability of these findings is limited to samples of families with young children.

In conclusion, given that early temperament has been linked to later eating problems (e.g. Martin et al., 2000; Wonderlich et al., 2004) and that children's early eating behaviours have been shown to be relatively stable (Ashcroft, Semmler, Carnell, van Jaarsveld \& Wardle, 2008), identifying associations between eating behaviours and temperamental traits at an early age could potentially be useful for clinicians and healthcare professionals working with children with feeding problems and with those who are, or are at risk of, overweight. These results imply that emotional children may exhibit eating behaviours which could make them more difficult to feed and may be more predisposed to have feeding problems. This 
may be associated with the feeding practices that parents use with their children and further work is needed to explore this. 


\section{REFERENCES}

Agras, W.S., Hammer, L.D., McNicholas, F. \& Kraemer H.C. (2004). Risk factors for childhood overweight: A prospective study from birth to 9.5 years. Journal of Pediatrics, 145(1), 20-25.

Ashcroft, J., Semmler, C., Carnell, S., van Jaarsveld, C.H.M., \& Wardle, J. (2008).

Continuity and stability of eating behaviour traits in children. European Journal of Clinical Nutrition, 62, 985-990.

Barkeling, B., Ekman, S., \& Rossner, S. (1992). Eating behavior in obese and normal weight 11-year-old children. International Journal of Obesity, 16, 355-360.

Blissett, J. \& Farrow, C. (2007). Predictors of maternal control of feeding at 1 and 2 years of age. International Journal of Obesity, 31, 1520-1526.

Blissett, J., Haycraft, E. \& Farrow, C. (2010). Inducing preschool children's emotional eating: Relations with parental feeding practices. American Journal of Clinical Nutrition, 92, 359-365.

Buss, A. H. \& Plomin, R. (1984). Theory and measurement of EAS. In Temperament: Early developing personality traits (pp. 84-104). Hillsdale, New Jersey: Lawrence Erlbaum Associates.

Chatoor, I., Ganiban, J., Hirsch, R., Borman-Spurrell, E. \& Mrazek, D.A. (2000). Maternal characteristics and toddler temperament in infantile anorexia. Journal of the American Academy of Child and Adolescent Psychiatry, 39(6), 743-751.

Child Growth Foundation (1996). Cross Sectional Stature and Weight Reference Curves for the UK. London, United Kingdom: Child Growth Foundation.

Farrow, C. \& Blissett, J. (2006). Maternal cognitions, psychopathologic symptoms and infant temperament as predictors of early infant feeding problems: A longitudinal study. International Journal of Eating Disorders, 39(2), 128-134. 
Hagekull, B., Bohlin, G., \& Rydell, A. M. (1997). Maternal sensitivity, infant temperament, and the development of early feeding problems. Infant Mental Health Journal, 18(1), 92106.

Haycraft, E.L. \& Blissett, J.M. (2008). Maternal and paternal controlling feeding practices: Reliability and relationships with BMI. Obesity (Silver Spring),16, 1552-1558.

Lobstein, T., Baur, L., \& Uauy, R. (2004). Obesity in children and young people: a crisis in public health. Obesity Reviews, 5(Suppl 1), 4-104.

Martin, G.C., Wertheim, E.H., Prior, M., Smart, D., Sanson, A., \& Oberklaid, F. (2000). A longitudinal study of the role of childhood temperament in the later development of eating concerns. International Journal of Eating Disorders, 27, 150-162,

Mathiesen, K. S. \& Tambs, K. (1999). The EAS temperament questionnaire: Factor structure, age trends, reliability and stability in a Norwegian sample. Journal of Child Psychology and Psychiatry, 40(3), 431-439.

Pliner, P. \& Loewen, E. R. (1997). Temperament and food neophobia in children and their mothers. Appetite, 28, 239-254.

Schaffer, H.R. (2006). Key concepts in developmental psychology. London, United Kingdom: Sage Publications.

Wardle, J., Guthrie, C. A., Sanderson, S., \& Rapoport, L. (2001). Development of the Children's Eating Behaviour Questionnaire. Journal of Child Psychology and Psychiatry, 42(7), 963-970.

Webber, L., Hill, C., Saxton, J., Van Jaarsveld, C.H., \& Wardle, J. (2009). Eating behaviour and weight in children. International Journal of Obesity, 33, 21-28.

Wonderlich, S.A., Connolly, K.M. \& Stice, E. (2004). Impulsivity as a risk factor for eating disorder behavior: Assessment implications with adolescents. International Journal of Eating Disorders, 36(2), 172-182. 
Table 1: Descriptive statistics for the whole sample of children on subscales of the Children's Eating Behaviour Questionnaire and EAS Temperament Survey.

Children $(\mathrm{N}=241)$

Mean (SD)

\section{Children's Eating Behaviour Questionnaire}

Food responsiveness

$2.20(0.64)$

Emotional over eating

$1.72(0.59)$

Enjoyment of food

$3.86(0.68)$

Desire to drink

$2.52(0.96)$

Satiety responsiveness

$2.94(0.64)$

Slowness in eating

$2.92(0.83)$

Emotional under eating

$2.76(0.90)$

Food fussiness

$2.70(0.81)$

\section{EAS Temperament Survey}

Shyness

$2.62(0.81)$

Emotionality

$2.57(0.94)$

Sociability

$3.57(0.65)$

Activity

$4.17(0.71)$

SD: Standard Deviation 
Table 2: One-tailed partial correlations, controlling for child age and gender, between children's eating behaviours, temperament and BMI $(N=241)$.

\section{Shyness Emotionality Sociability Activity Child BMI^}

\section{Food approach}

$\begin{array}{llllll}\text { Food responsiveness } & -.007 & .065 & .052 & .031 & .324^{* *} \\ \text { Emotional over eating } & .096 & .156^{*} & -.007 & -.067 & .237^{*} \\ \text { Enjoyment of food } & .015 & -.291^{* *} & -.008 & .099 & .141 \\ \text { Desire to drink } & -.011 & .108 & .006 & .053 & .323^{* *}\end{array}$

\section{Food avoidant}

\begin{tabular}{|c|c|c|c|c|c|}
\hline Satiety responsiveness & -.033 & $.354 * *$ & -.007 & -.097 & -.125 \\
\hline Slowness in eating & -.013 & $.236 * *$ & -.045 & -.113 & $-.213 *$ \\
\hline Emotional under & .034 & $.194 * *$ & .132 & -.146 & .073 \\
\hline \multicolumn{6}{|l|}{ eating } \\
\hline Food fussiness & .063 & $.250 * *$ & .022 & -.091 & -.041 \\
\hline Child BMI^ & .099 & -.122 & -.163 & -.002 & -- \\
\hline
\end{tabular}

